\title{
Landscaping co-design: digital fabrication as communication among designers, visually impaired people and children
}

XXIV International Conference

of the Iberoamerican Society

of Digital Graphics

Medellin | Colombia

\author{
Andréa Quadrado Mussi \\ IMED | Brasil | andrea.mussi@imed.edu.br \\ Daiara lasmin Rodrigues \\ IMED | Brasil | daiarar@hotmail.com \\ Priscila Castioni Isele \\ IMED | Brasil | Priscila.cationi@hotmail.com \\ Alana Arena Schneider \\ IMED | Brasil | arqui.alana.arena@gmail.com
}

\begin{abstract}
Children's playgrounds, intended for recreation and significant for the inclusion and mobility of children, through inclusive urban equipment that stimulate new experiences for cognitive development. In order to gather suggestions through a co-design with visually impaired people and children, to develop the landscaping co-design at Square Capitão Jovino. This article describes some activities carried out in the design processes, emphasizing the importance of an inclusive project based on their daily experiences. This article is a follow-up of the actions already carried out for requalification in the square (nine years ago), with the support of Higher Education Institution and Blind Association.
\end{abstract}

Keywords: Design process; Digital fabrication; Co-design; Visually impaired people.

\section{INTRODUÇÃO}

Desde 2013 há parceria entre uma Instituição de Ensino e uma Associação de Cegos. As atividades desenvolvidas desde então, são sobre a inclusão das Pessoas com Deficiência Visual (PcDV) no processo de projeto de arquitetura, urbanismo, paisagismo e interiores, na formatação de metodologia de codesign e de ferramentas de representação e antecipação do ambiente construído por meio do uso de fabricação digital e automação. Esse artigo apresenta parte das ações para delinear metodologia de codesign em paisagismo, a partir de requalificação de playground de duas praças em cidades de pequeno e médio porte brasileiras, envolvendo a interação entre comunidade local, projetistas, crianças e PcDV no processo de projeto (MUSSI et al., 2016, MUSSI et al., 2019). A Praça Capitão Jovino foi requalificada em 2011 numa parceria público/privada com ações bottom-up, coordenada pela Associação de amigos da praça da Santa Teresinha (MUSSI, 2018).

O presente artigo tem por objetivo fazer uso de novos métodos de Codesign de paisagismo empregados na inclusão de PcDV (Pessoas com Deficiência Visual) no Processo de Projeto (PP) de paisagismo, focando em crianças com deficiência visual nos playgrounds infantis. $\mathrm{O}$ estudo centra-se no playground da Praça Capitão Jovino (Figura 1), sendo que a última requalificação ocorreu há nove anos não incorporando a acessibilidade universal, necessitando de nova requalificação (MUSSI, 2018). Os alunos da Escola Notre Dame Menino Jesus, localizada em frente à Praça, a utilizam com frequência em conjunto aos demais moradores do bairro Rodrigues. A proposta busca através de um design universal, promover a inclusão social de diferentes públicos.

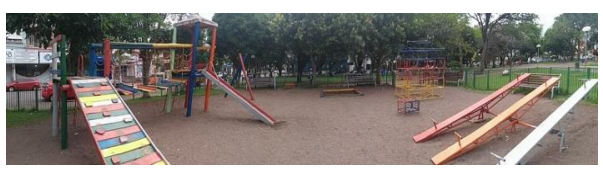

Figura 1: Situação atual playground.

Segundo Alegre (1995), a partir de experiências adquiridas pelas informações sensoriais, pessoas estabelecem seus conceitos sobre o universo, em geral através da conservação da memória sobre suas vivências diárias, sendo mais relevante as praticadas com mais frequência em conjunto ao uso do principal sensor, sendo em $85 \%$ o visual. Com a ausência da visão, crianças com deficiência visual exploram outros sentidos para sua orientação espacial como o tato, olfato e audição, que podem ser desenvolvidos e explorados nos espaços urbanos inclusivos.

Medeiros e Nunes (2016) comentam que espaços públicos são ambientes com convivência múltipla, como as praças inclusivas, lugares caracterizados por serem um local onde todos têm direito a acessibilidade e interação. Estes espaços exercem um papel de proximidade da sociedade com as PcDV, em que a inclusão se inicia com a 
acessibilidade aos locais, vinculados com as infraestruturas presentes e suas normativas aplicadas em cada espaço público, como por exemplo nos equipamentos e mobiliários urbanos.

Referente a playgrounds inclusivos, Muller (2019) ressalta como são significativos no desenvolvimento da inclusão de crianças com deficiência visual, os espaços públicos, por possuírem um design universal considerando todas as crianças, com ou sem deficiência. Promovendo um convívio múltiplo, onde crianças com deficiência visual podem se divertir da mesma maneira do que os demais, incentivando também o respeito as diferenças, através de brinquedos inclusivos, contribuindo também, com o lazer e desenvolvimento cognitivo das mesmas.

\section{METODOLOGIA}

Para a realização do projeto de requalificação da Praça Capitão Jovino, a principal metodologia utilizada foi explorar a participação dos usuários no Processo de Projeto (PP), contribuindo para a formatação da metodologia geral de Codesign (Figura 2) que vem sendo construída pelo Núcleo de Inovação em Tecnologia em Arquitetura e Urbanismo (MUSSI et al., 2019, 2020) e neste artigo em especial do Codesign em paisagismo. As pessoas envolvidas são crianças, PcDV, comunidade local e profissionais da área que auxiliaram nas tomadas de decisões durante o PP. A Figura 3 sistematiza as pessoas envolvidas e respectivas atividades e métodos empregados, bem como as etapas que terão seus resultados apresentados neste artigo (em cinza são etapas ainda em andamento). Para Caixeta e Fabrício (2018) o Codesign somado a outros métodos são um processo de elaboração de projetos e produtos aplicados na arquitetura entre os designers e usuários, com objetivo de integrar os mesmos na elaboração de projetos, cujos processos favorecem a criação conjunta e tornam os resultados adequados e mais assertivos.

O Codesign entre projetistas e crianças ocorreu na formatação de Workshop e Focus Group, consistindo na interação em grupo, objetivando validação dos assuntos propostos (MARTIN, HANINGTON, 2012). Assim, foram realizadas cinco atividades com um grupo de cem crianças da Escola Notre Dame Menino Jesus, em dois momentos para que as atividades fossem realizadas com um total de cinquenta crianças por vez em grupos de dez, distribuídos em cada uma das cinco estações de atividades (denominadas de $\mathrm{A} 1 \mathrm{a} \mathrm{A} 5$ )

A atividade A1: Dotmocracy de brinquedos (Figura 4) fez com que os alunos avaliassem vinte e oito brinquedos selecionados em pesquisas e visitas in loco no Brasil e exterior, com as opções amei, curti ou não curti, utilizandose de Preferência Declarada ao escolher entre suas predileções (BRANDLI, HEINECK, 2005). Já na atividade A2: Desenho seu brinquedo preferido (Figura 5) foi utilizada a Preferência Revelada, aonde cada criança desenhou o brinquedo que gostaria de ter no playground, revelando o que imaginavam sobre o tema. As atividades A3: Brinquedo de texturas (Figura 6) e A4: Brinquedo de pesos (Figura 7) instigaram os sentidos das crianças ao realizá-las vendadas. Respectivamente, as atividades estimularam o tato e percepção sobre diferentes pesos. Enquanto a atividade A5: Brinquedo de sons estimulou a audição pelos diferentes sons produzidos (Figura 8). Para validação do resultado das atividades realizou-se entrevista semiestruturada com Terapeuta Ocupacional.

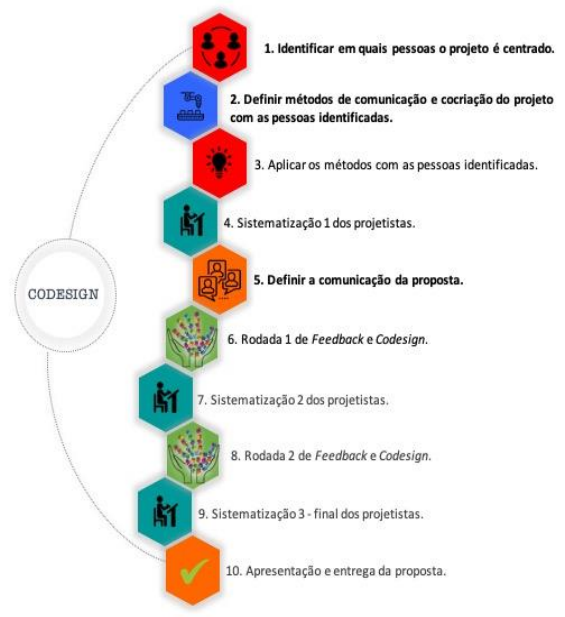

Figura 2: Metodologia geral do Codesign.

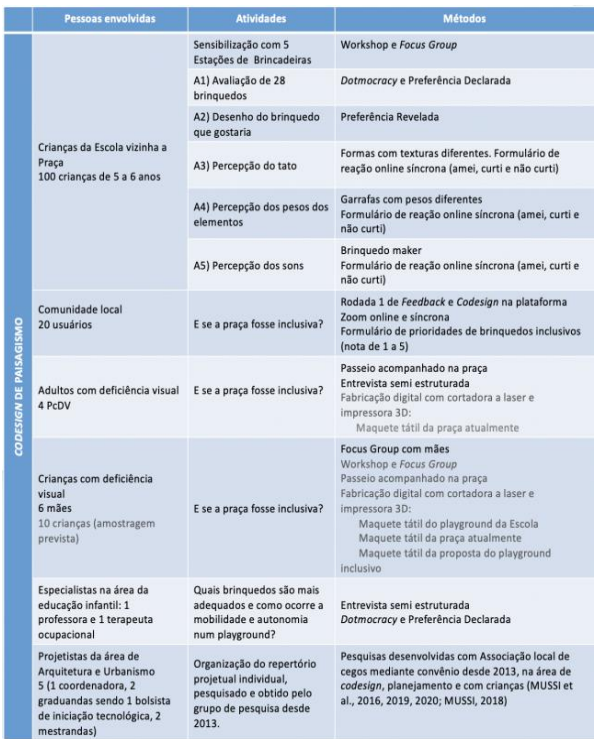

Figura 3: Sistematização do codesign em paisagismo. Em cinza ações a serem realizadas.

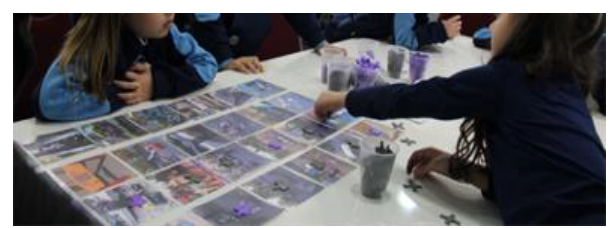

Figura 4: Atividade A1: Dotmocracy de brinquedos. 


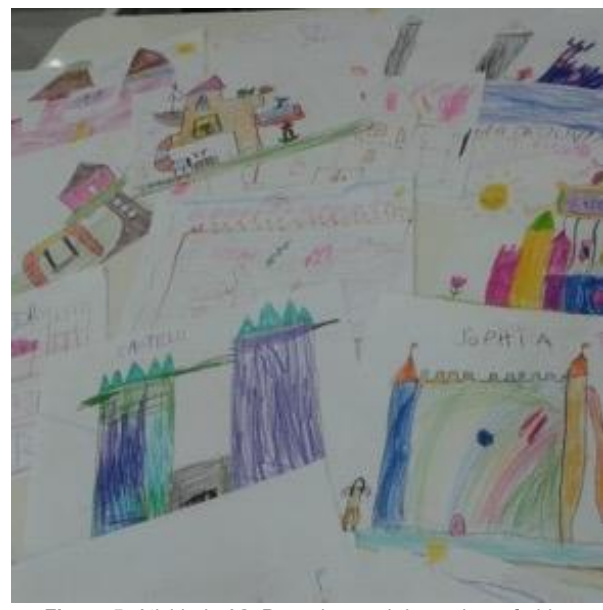

Figura 5: Atividade A2: Desenho seu brinquedo preferido.

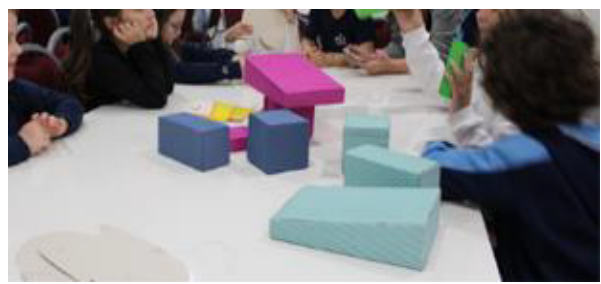

Figura 6: Atividade A3: Brinquedo de texturas.

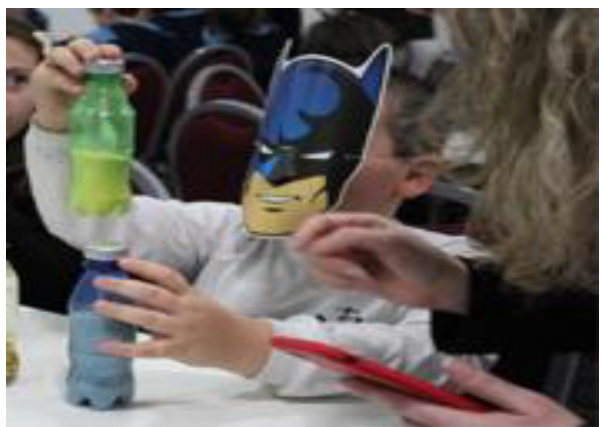

Figura 7: Atividade A4: Brinquedo de pesos.

Segundo Dischinger (2000), os passeios acompanhados têm como objetivo analisar experiências de pessoas com alguma deficiência em determinados ambientes e despertar novas sugestões por parte dos usuários nos PP. Foi realizado passeio acompanhado com três adultos de uma Associação para cegos da cidade em que se localiza a Praça, buscando sua percepção sobre a mesma como um todo e também sugestões para o playground (Figura 9).

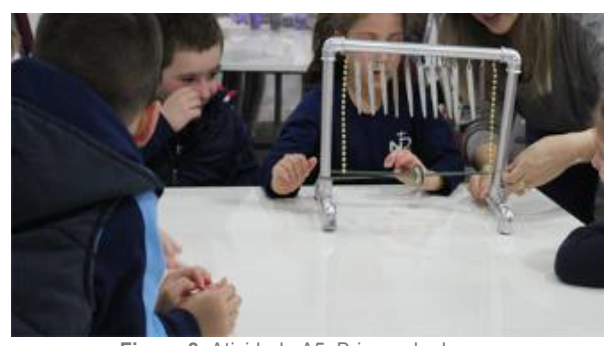

Figura 8: Atividade A5: Brinquedo dos sons.

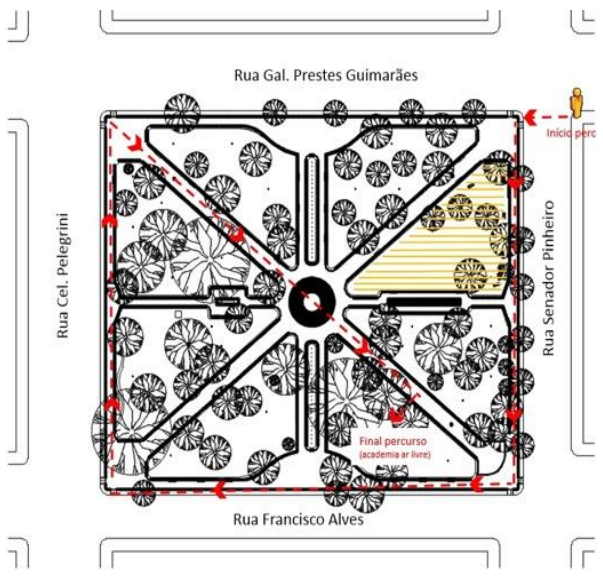

Figura 9: Percurso do passeio acompanhado, com playground demarcado. Fonte: Autores, 2019.

O passeio acompanhado na praça resultou em uma maquete tátil sugerida pelas PcDV como método para seu entendimento espacial do local. Também foram realizadas maquetes táteis em impressora 3D de playground da Escola Frei Wilson João e do playground da Praça Mário Bernardi da cidade vizinha Marau, possibilitando o entendimento dessa metodologia pelos alunos da educação infantil. Estas estão sendo utilizadas como objeto de estudo e passarão por processo de aperfeiçoamento ao longo da pesquisa, que busca por meta a longo prazo um modelo padrão de praças inclusivas para a região.

Fabricadas digitalmente no software SketchUp, posteriormente foram trabalhadas nos softwares Revit e Tinkercad para possibilitar a leitura correta da impressora Sethi 3D com sistema FDM (Fused Deposition Modelling). Por fim, foram realizadas entrevistas com quatro PcDV, sendo 2 homens e 2 mulheres voluntárias, uma terapeuta ocupacional que atua em conjunto a crianças com deficiência visual e mobilidade reduzida e a professora da Escola Frei Wilson João, que acompanha crianças com deficiência visual. Foram realizadas através de áudio, transcritas e analisadas de forma qualitativa, com objetivo de proporcionar novas considerações para o projeto de reforma do playground inclusivo, a partir da experiência diária dos entrevistados.

As metodologias do Codesign em paisagismo ocorreram em duas cidades, inicialmente centrou-se na cidade de Passo Fundo e como desenvolvimento futuro na cidade 
vizinha Marau. Os passeios acompanhados aconteceram na cidade de Passo Fundo, havendo em outra etapa da pesquisa, na cidade vizinha, demais passeios acompanhados dando continuidade ao projeto. As entrevistas realizadas aconteceram na cidade vizinha, em que proporcionaram contribuições sobre Playgrounds inclusivos.

A comunidade local do bairro Rodrigues da Praça Capitão Jovino participou em ação online síncrona e conferiu nota de 1 a 5 a cada um dos brinquedos inclusivos (ver etapa na Figura 5).

\section{RESULTADOS E DISCUSSÕES}

Atividades com as crianças

A coleta de opiniões da atividade A1 revelou onze brinquedos que as crianças preferiram, sendo eles em ordem: a estação de água, placa tátil, balanço cesta, escalada no escorregador e o balanço inclusivo empatados, estação de areia, placa tátil, túnel e piso desenhável a giz também empatados, pula-pula, estação de lama e escorregador em talude (Figuras 10, 11, 12, 13, 14 e 15).
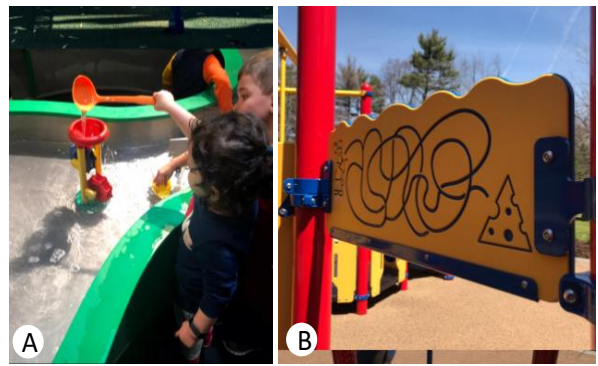

Figura 10: A) Estação de água, B) Placa Tátil.

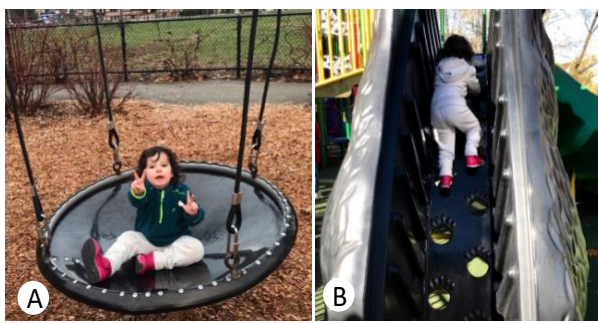

Figura 11: A) Balanço cesta, B) Escalada no escorregador.

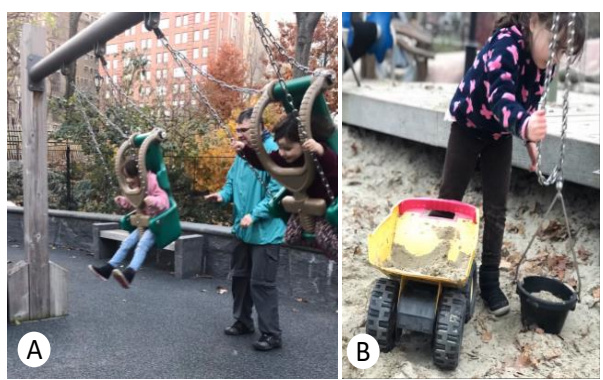

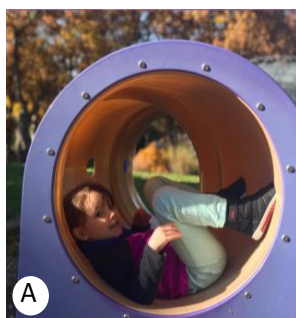

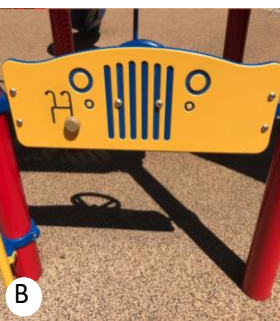

Figura 13: A) Placa tátil, B) Túnel.

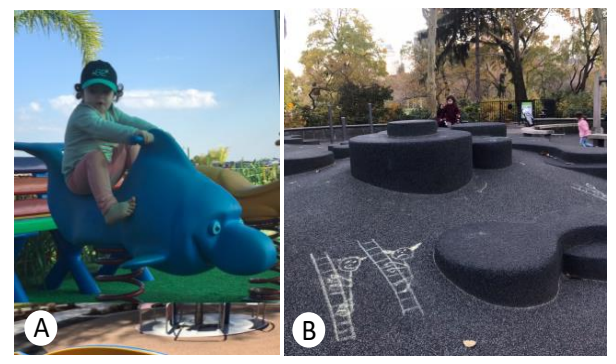

Figura 14: A) Piso desenhável a giz, B) Pula-pula.

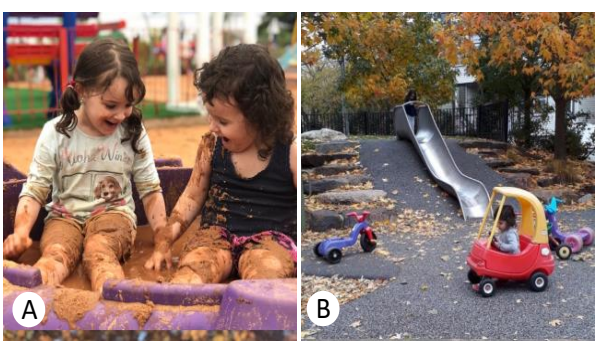

Figura 15: A) Estação de lama, B) Escorregador em talude.

$\mathrm{Na}$ atividade $\mathrm{A} 2$ as crianças em sua maioria replicaram os brinquedos que estão acostumados a utilizar nos parquinhos, os personalizando ou algumas os uniram em uma estação. Demonstrando a falta de diversidade dos playgrounds da região, já que as crianças desenharam baseadas no que encontram nesses espaços de lazer, usando suas referências.

As atividades A3 e A5 tiveram a reação amei (mais alta da coleta de opiniões) de mais de $70 \%$ das crianças, já a atividade A4 foi amada por 37\%, tendo também um maior índice de rejeição com reação não curti (mais baixa da coleta de opiniões) (Figuras 16, 17 e 18).

Figura 12: A) Balanço inclusivo, B) Estação de areia. 


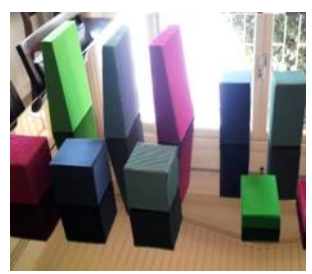

- AMEI $=$ CURTI NÃO CURTI

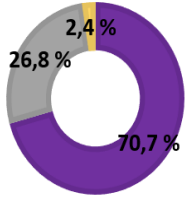

Figura 16: Repostas da A3: Brinquedo de texturas.

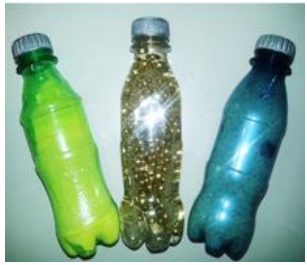

-AMEI $=$ CURTI $=$ NÃOCURTI

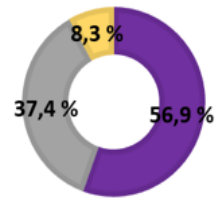

Figura 17: Repostas da A4: Brinquedo de pesos.

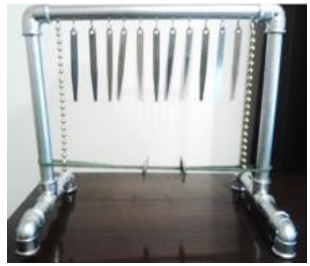

$\square$ AMEI $=$ CURTI $=$ NÃOCURTI

Figura 18: Respostas da A5: Brinquedo de sons.

\section{Atividade com as PcDV}

No passeio acompanhado foi relatado que apesar da Praça possuir piso diferente e identificado com a cor vermelha (perceptível a PcDV que possuem um baixo grau de visão) como guia, eles relataram que preferem utilizar as guias de balizamento existentes (cordão dos canteiros) para se locomover. Também comentaram sobre a distribuição dos acessos em cruz cortada ao centro por duas linhas perpendiculares, que dificultam a identificação da posição geográfica na Praça, possivelmente por serem espelhados não podendo ser facilmente diferenciados. Uma sugestão foi o alinhamento das guias de balizamento do acesso que se apresentam em ângulo com as guias da calçada que são retas. Nestes caminhos os bancos e lixeiras poderiam estar recuados, ou seja, são obstáculos a locomoção.

Relataram que o que mais desejam é uma maquete tátil do espaço nos acessos e centro da praça aonde se distribuem os caminhos, já que se locomovem pelas suas memórias do espaço, então a maquete anteveria a locomoção. Foi citada a academia ao ar livre como uma atividade que gostariam que estivesse bem demarcada, além dos acessos e parada de ônibus. Também a maquete do playground para as crianças se locomoverem nele seria muito benéfica (Figura 19).
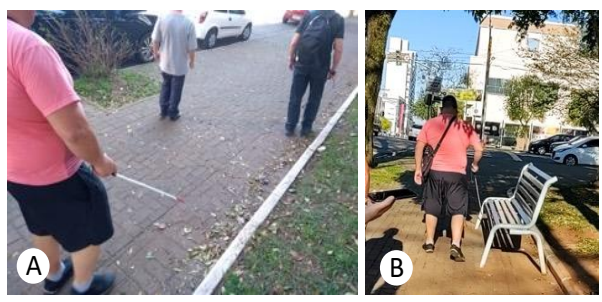

Figura 19: A) Meio fio utilizado como guia de percurso, B) Banco da praça como obstáculo.

\section{Maquetes táteis}

Confeccionou-se modelo 3D de maquete tátil teste como representação da Praça, com a indicação das diferenças de níveis, num primeiro momento, possibilitando o entendimento dos PcDV pelo tato do local como um todo, já que não possuem essa percepção de forma visual. Este quesito é visto pelos mesmos como um ponto positivo desta praça da cidade, pois não possui desníveis. Assim, foram representados os caminhos e canteiros de forma plana como uma diferenciação de $5 \mathrm{~mm}$ para representação adequada da situação real do local. Em pesquisas anteriores plantas táteis e maquetes táteis de ambientes internos e externos já foram testadas com êxito para antecipar a memória espacial de diversas localidades (MUSSI et al., 2019, 2020). Porém, nesta fase especificamente seria testada a maquete da praça existente e da proposta, para ambas serem comparadas entre si como foi feito em Codesign arquitetônico em outra ocasião (MUSSI et al., 2019).

Posteriormente de forma sequencial, serão incluídos os obstáculos significativos nos percursos, como bancos, monumentos e vegetações altas (árvores) representadas por depressões circulares para facilitar o processo de tatear a maquete, nas quais modelos $3 \mathrm{D}$ de árvores poderão ser encaixados para total compreensão.

As maquetes da cidade vizinha contribuirão para o processo de Codesign com crianças e PcDV, compreendendo a percepção que as crianças possuem através da metodologia de maquete tátil para interpretação dos playgrounds. Através da comparação entre o playground da Escola que é de seu convívio representado em uma maquete e comparado com outra maquete que representa a Praça objetivada no estudo que não pertence à convivência diária das crianças (Figuras 20 e 21).

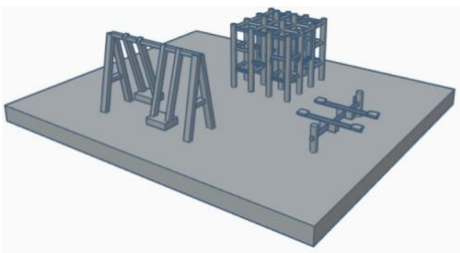

Figura 20: Vista superior de maquete de Praça Mário Bernardi (software Tinkercad). 


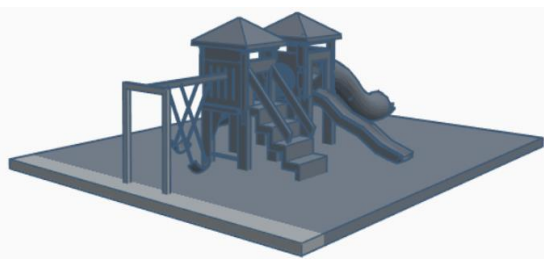

Figura 21: Perspectiva de maquete de playground da Escola Frei Wilson João (software Tinkercad).

\section{Especialistas na área da educação infantil}

Através das entrevistas semiestruturadas pôde-se adquirir informações e dados essenciais para o projeto, realizadas através de questionários via áudio e transcritas, analisadas de forma qualitativa, com quatro PcDV, uma terapeuta ocupacional e uma professora, atuantes na área. Servindo como guia para melhor compreensão do projeto e tendo como objetivo analisar a opinião de usuários e profissionais sobre os espaços como demonstra os infográficos abaixo.

$\mathrm{Na}$ entrevista com as PcDV observou-se principalmente as experiências diárias de PcDV com os espaços urbanos para contribuição neste artigo, que em momentos instigou a participação com sugestões sobre os espaços, especialmente ligadas a um projeto conjunto, para ouvir as opiniões dos usuários e para assim, poder compreender mais sobre as suas necessidades como demonstra no infográfico (Figura 22).

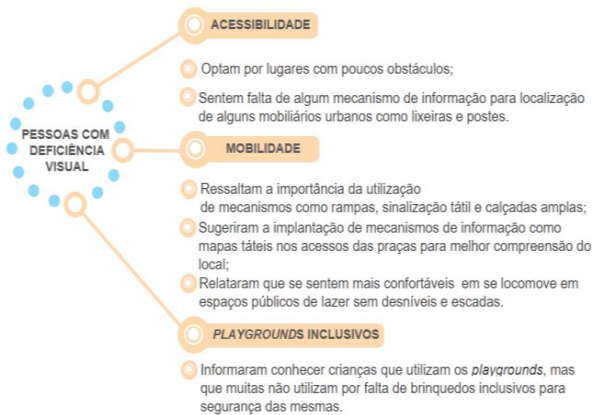

Figura 22: Infográfico das respostas às entrevistas com PcDV .

A entrevista com a Terapeuta Ocupacional foi de imensa importância, principalmente para um maior conhecimento sobre as dificuldades das crianças com deficiência visual nesses espaços urbanos, e entendimento a respeito dos brinquedos inclusivos para a elaboração deste artigo como demonstra o infográfico abaixo com os principais tópicos explorados na entrevista.

A primeira pergunta foi relacionada as melhores tipologias de brinquedos a partir das imagens demonstradas à entrevistada. Em que a entrevistada citou como tipologias mais inclusivas os brinquedos da Figura 23, por serem diversificadas e promoverem a inclusão e o desenvolvimento cognitivo das crianças com diferentes formas de brincar.

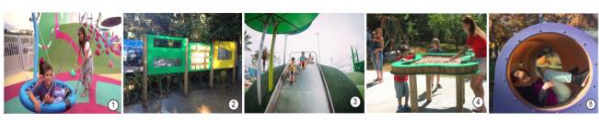

Figura 23: Tipologia de brinquedos classificados como mais inclusivos.

A entrevistada também citou que uma das principais preocupações na concepção de playgrounds inclusivos deve ser a segurança, como os brinquedos da Figura 24 em que há escaladas, onde a mesma citou que a criança não só tem a deficiência visual mas tem a mobilidade motora reduzida, havendo problemas em seu equilíbrio, podendo causar acidentes futuros, sendo estes brinquedos um pouco inseguros para crianças com mobilidade reduzida (Figura 25).
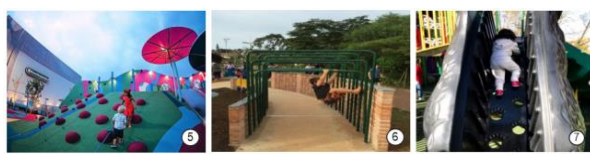

Figura 24: Tipologia de brinquedos classificados como menos inclusivos.

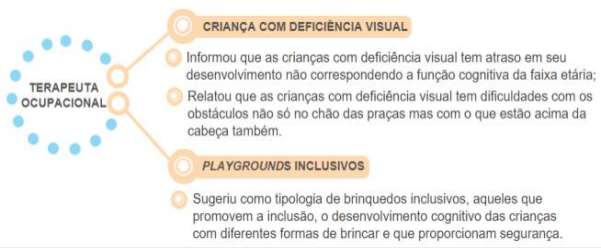

Figura 25: Infográfico das respostas às entrevistas com TO.

Concluindo, a entrevista com a professora responsável pelo acompanhamento das crianças com deficiência visual na Escola Frei Wilson João foi essencial para um maior entendimento principalmente sobre a funcionalidade das atividades com crianças com deficiência visual na escola, das brincadeiras e o acesso ao Playground (Figura 26).

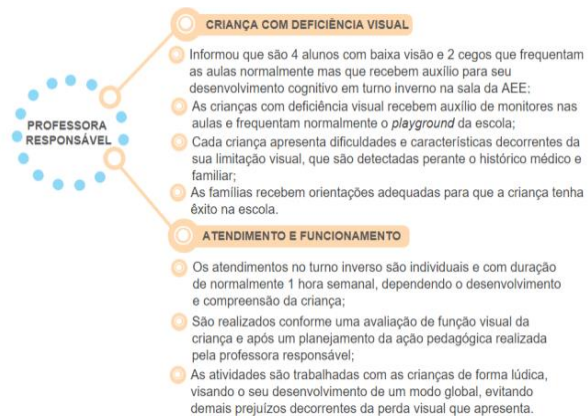

Figura 26: Infográfico das respostas à entrevista com professora.

A entrevista com a terapeuta ocupacional (TO) para validação das atividades realizadas com as crianças fez com que se elenca-se alguns itens importantes a serem observados no projeto e tipologia dos brinquedos escolhidos, : (i) os modelos de balanços para crianças com deficiências físicas devem ter encosto almofadado para segurar a cabeça e disponibilização de cinto de segurança; (ii) destacou a importância de acrescentar texturas através 
de plantas diferenciadas com aromas ou não, pois são muito importantes para crianças com autismo e com deficiência visual; (iii) relatou também que seria interessante a informação em forma de desenho ou escrita de como utilizar cada brinquedo; (iv) um dos motivos das crianças terem escolhido escorregador, túnel e escalada com laterais (guarda corpos) mais generosos é benéfico para crianças com espectro autista e com deficiência visual por dar mais segurança, aconchego e delimitar uma área de abrangência mais focada sem muitas outras informações; e (v) o balanço cesto oportuniza rica atividade sensorial com segurança para várias faixas etárias.

\section{Projeto}

Realizou-se projeto de paisagismo para o playground da Praça Capitão Jovino baseado em todas as informações coletadas com a metodologia de Codesign. Primeiramente ampliou-se a área do projeto, que atualmente ocupa uma parcela do canteiro em que está localizado possibilitando um layout melhor estruturado para atender os diferentes públicos infantil e com um aumento significativo no número de brinquedos. Foram selecionados vinte e oito brinquedos de acordo com as preferências das crianças observadas no Focus Group, e nas especificações técnicas dadas pela TO entrevistada, resultando em brinquedos esteticamente atrativos, com os devidos cuidados para atender a diversidade de crianças como, por exemplo, balanços com cintos de segurança e apoio para a cabeça, brinquedos com espaços para cadeiras de rodas quando necessário, inclusão de brinquedos para deficientes cognitivos que são difíceis de serem encontrados e estímulo dos sentidos e coordenação motora. A especialista também ressaltou a integração com a natureza como extremamente positiva para desenvolver os sentidos, sendo incluída em recortes no piso emborrachado que lembra a temática da preservação dos rios em APPS (Áreas de Preservação Permanente), devido a um importante rio da cidade e também em parede de vegetação utilizada juntamente com placas táteis para esconder locais perigosos (Figuras 27 e 28).

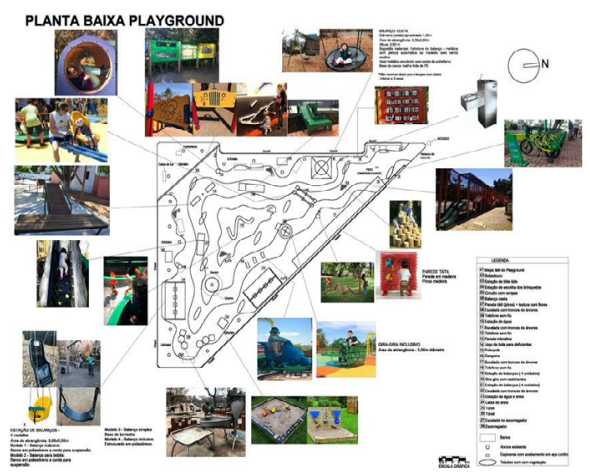

Figura 27: Etapa 4 do Codesign: Sistematização 1 dos projetistas do playground da Praça Capitão Jovino.

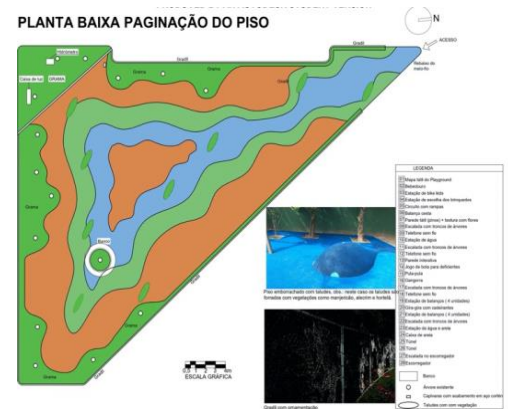

Figura 28: Estudo preliminar de paginação de piso do playground da Praça Capitão Jovino.

\section{Comunidade Local}

A Etapa 4 de Sistematização 1 do projeto pelos projetistas foi iniciada com um workshop online síncrono com a comunidade local, com vinte participantes. Dos brinquedos empregados os que obtiveram notas mais altas foram: balanço inclusivo (100\%), gangorra para pessoas com mobilidade reduzida $(100 \%)$, gira gira para cadeirantes $(90 \%)$, túnel $(81 \%)$, estação de bicicletas compartilhadas (81\%), telefone sem fio (72\%), estação de escolha de brinquedos $(72 \%)$, escalada com escorregador $(63 \%)$, balanço cesta (63\%), circuito com rampas $(63 \%)$ e estação de água (54\%).

O balanço inclusivo, escalada com escorregador, estação de água, túnel e balanço cesta condizem com os brinquedos elencados pelas crianças. O túnel, o balanço cesta e a estação de escolha de brinquedos foram elencados pelo TO como entre os mais inclusivos.

\section{CONCLUSÕES}

Foram utilizados alguns métodos, ferramentas e recursos de Codesign como os Focus Group, Passeios Acompanhados e Entrevistas Semiestruturadas, sendo os dois primeiros métodos práticos ao envolver o usuário com o ambiente. E as entrevistas semiestruturadas com voluntários abrangendo uma visão técnica. O objetivo geral da utilização dessa metodologia é envolver o usuário no processo de projeto em paisagismo e proporcionar uma visão mais adequada aos projetistas para realizar um design universal, atendendo as diferentes necessidades humanas. Além de o usuário interagir com o projeto, as crianças sem deficiência visual puderam instigar outros sentidos além da visão por meio de brincadeiras vendados, tornando a metodologia de projeto já inclusiva.

Esses processos metodológicos resultaram em projeto de estudo de paisagismo da Praça Capitão Jovino realizado em 2019, o qual ganhará novas contribuições com a validação da maquete tátil pelos PcDv que destacaram sua necessidade durante o Passeio Acompanhado e do projeto pela comunidade do bairro em que a Praça se localiza, frequentadores da mesma, além da contribuição de estudo de playground acessível na cidade vizinha Marau. Objetivando futura produção de um modelo padrão para implantação em playground da região, explicitado no artigo a precariedade desses espaços, principalmente com a constatação de que crianças e adultos com deficiências visuais ou cognitivas não frequentam costumeiramente 
espaços de lazer públicos e abertos devido ao despreparo dos mesmos.

A tecnologia demonstra-se como uma importante aliada na precipitação desses espaços ao serem representados de forma tridimensional em escala reduzida, por meio de impressão 3D as pessoas com deficiência visual que necessitam da memorização mental para locomover-se por eles.

A proposta do playground foi realizada pelos projetistas considerando as interações realizadas até o momento. As decisões projetuais estão em andamento e consistem na interação entre as PcDV por meio dos recursos de representação (maquetes e plantas táteis) para as alterações e melhorias no projeto, bem como com especialistas, crianças e os seus responsáveis. Os brinquedos projetados buscam atender as necessidades e serem em grande parte fabricados digitalmente e de fácil reprodução, estimulando ações bottom-up da comunidade, a exemplo do que ocorreu na requalificação anterior de uma das praças (MUSSI, 2018).

\section{AGRADECIMENTOS}

Agradecemos a Associação Passofundense de Cegos - APACE, a Escola participante e os entrevistados pela importante contribuição científica a este trabalho de pesquisa; a Fundação IMED; o Núcleo de Inovação e Tecnologia em Arquitetura e Urbanismo (NITAU) do Programa de Pós-graduação em Arquitetura e Urbanismo da IMED (PPGARQ/IMED); e o Conselho Nacional de Desenvolvimento Científico e Tecnológico - CNPq.

\section{REFERÊNCIAS}

BRANDI, L. L.; HEINECK, L. F. M. (2005, Abr/Jun). As abordagens dos modelos de preferência declarada e revelada no processo de escolha habitacional. Ambiente Construído, Porto Alegre, (5) 2, 61-75.

CAIXETA, M. C. B. F.; FABRICIO, M. M (2018, jan/mar). Métodos e instrumentos de apoio ao codesign no processo de projeto 111 de edifícios. Ambiente Construído, Porto Alegre, (18) 1, 110-131.

DISCHINGER, M (2000). Designing for all senses: Accessible spaces for visually impaired citizens. Goteborg, Sweden.
2000. 260 p. Thesis (for the degree of Doctor of Philosophy) Department of Space and Process School of Architecture, Chalmers University of Technology.

MARTIN, B.; HANINGTON, B. (2012). Universal Methods of Design. Beverly: Rockport.

MEDEIROS, B. L. D. de; NUNES, T. C. (2016). Acessibilidade e Inclusão em Espaços Coletivos de Lazer. In: VI ENCONTRO NACIONAL DE ERGONOMIA DO AMBIENTE CONSTRUÍDO E VII SEMINÁRIO BRASILEIRO DE ACESSIBILIDADE INTEGRAL, 78., 2016, Recife. Eneac Ano 10. Recife: Eneac, $1-12$.

MÜLLER, M.S (2019). Especificações projetuais para o desenvolvimento de equipamentos para playground inclusivo e acessível. 2019. 383f. Tese (Doutorado em Design) - Escola de Engenharia, Universidade Federal do Rio Grande do Sul, Porto Alegre.

MUSSI, A. Q.; SILVA, L. B. O.; LANTELME, E. M. V. ; CESARO S. R. ; DEON, L. ; RODRIGUES, D. I.; SILVA, T. L. (2020). Arquitetura inclusiva: experiência de projeto colaborativo. AMBIENTE CONSTRUÍDO (ONLINE), (20), 367-386.

MUSSI, A. Q.; SILVA, T. L. ; ZARDO, P. ; SILVA, J. L.; PAZINI, E Z. ; FERRI, M.; MOREIRA, D. (2019). Ferramentas de incremento do bem-estar de pessoas com deficiência visual: arquitetura inclusiva e maquete tátil. ARQUITETURAREVISTA (UNISINOS), (15), 1-14.

MUSSI, A. Q. (2018). Contemporary urban planning: the importance and consequences of citizen participation in the processes and decisions about urban space. INTERAÇÕES, (19), 699-712

MUSSI, A. Q.; ROMANINI, A. ; LANTELME, E. M. V. ; MARTINS M. S. (2016). Arquitetura inclusiva: a planta tátil como instrumento de projeto colaborativo com portadores de deficiência visual. In: XX Congreso de la Sociedad Iberoamericana de Gráfica Digital, SIGraDI: crowdthingking, 2016, Buenos Aires. Proceedings..., 307-312.

SOBRE A DEFICIÊNCIA VISUAL. A deficiência visual. Disponível em: http://www.deficienciavisual.pt/txt-adeficienciavisual.htm. Acesso em: 10 mai. 2020. 